\title{
İşe Angaje Olma ve Algılanan İçsellik Statüsü İlişkisinde Çalışan Sesliliğinin Aracı Rolü
}

\author{
Mehtap Öztürk ${ }^{1 *}$ \\ ${ }^{1}$ Selçuk Üniversitesi, İktisadi ve İdari Bilimler Fakültesi, İşletme Bölümü, Konya, Türkiye (ORCID: 0000-0001-8513-9842)
}

(İlk Geliş Tarihi 3 Mayıs 2020 ve Kabul Tarihi 26 Haziran 2020)

(DOI: 10.31590/ejosat.735924)

\begin{abstract}
ATIF/REFERENCE: Öztürk, M. (2020). İşe Angaje Olma ve Algılanan İçsellik Statüsü İlişkisinde Çalışan Sesliliğinin Aracı Rolü. Avrupa Bilim ve Teknoloji Dergisi, (19), 614-622.

\section{$\ddot{O} \mathbf{z}$}

Pozitif örgütsel davranış konuları arasında yer alan ve çalışma ilişkilerinde çalışanların rol gereklerinin bir sonucu olarak ortaya çıkan işe angaje olma, çalışanların performansları başta olmak üzere birçok örgütsel sonuç üzerinde etkisi bulunan bir davranış türüdür. Bu nedenle çalışanların örgütlerdeki rol gereklerinin hangi öncüller tarafindan belirlendiğinin araştırılması önem taşımaktadır. İşe angaje olmanın önemli öncülleri arasında çalışan sesliliği gelmektedir. Algılanan içsellik statüsü ise örgütsel davranış yazınındaki çalışmalarda nispeten daha az ilgi görse de işe angaje olmanın bir diğer önemli öncülüdür. Bu kapsamda bu çalışmanın amacı, algılanan içsellik statüsünün işe angaje olma üzerindeki etkisinin incelenmesi ve bu ilişkide çalışan sesliliğinin etkisi olup olmadığının araştırılmasıdır. Araştırmada Konya örnekleminde bilişim sektöründe çalışan 403 çalışandan basit tesadüfi örnekleme yoluyla anket yöntemi ile veri toplanmıştır. Araştırma değişkenlerini ölçümlemek için işe angaje olma ölçeği (Schaufeli ve Bakker, 2003), çalışan sesliliği ölçeği (Van Dyne ve Le Pine, 1998) ve algılanan içsellik statüsü ölçeği (Stamper ve Masterson, 2002) kullanılmıştır. Örneklemden elde edilen veriler yapısal eşitlik modeli ile ve SPSS 23.0 ve AMOS 22.0 paket programları aracılığıyla analiz edilmiştir. Araştırma sonucunda algılanan içsellik statüsünün ve çalışan sesliliğinin işe angaje olma üzerinde pozitif yönlü ve istatistiksel bakımdan anlamlı bir etkisi olduğu tespit edilmiştir. Benzer şekilde algılanan içsellik statüsünün çalışan sesliliği üzerindeki etkisinin de pozitif yönlü ve istatiksel bakımdan anlamlı olduğu gözlemlenmiştir. Ayrıca çalışmada algılanan içsellik statüsü ve işe angaje olma arasındaki ilişkide çalışan sesliliğinin kısmi aracılık rolüne sahip olduğu sonucuna ulaşılmıştır. Bu doğrultuda, yüksek düzeyde içsellik statüsü algısına sahip çalışanların örgütsel uygulamalara daha fazla katılım sağlayarak seslilik davranışlarını artacağını ve bu durumun bir sonucu olarak çalışanların rol gereklerine angaje olacakları ifade edilebilir.
\end{abstract}

Anahtar Kelimeler: İşe Angaje Olma, Çalışan Sesliliği, Algılanan İçsellik Statüsü.

\section{Job Engagement and Perceived Insider Status: The Mediating Role of Employee Voice}

\begin{abstract}
Job engagement which is one of the positive organizational behavior issues and arises as a result of the role indicates of employees in labor relations is a type of behavior that has an impact on many organizational outcomes, especially on employee performance. Accordingly, it is important to investigate which antecedents are determined by the organizational role of the employees. Employee voice is an important antecedent of job engagement. On the other hand, perceived insider status is another important antecedent of job engagement, although it receives relatively less interest in the studies in the organizational behavior literature. In this context, the main purpose of this study is to explore the effects of the perceived insider status on job engagement and whether employee voice behaviour has mediating role on these relations. The data were collected with using survey method with simple random sampling from 403 employees in the information sector in Konya sample. Job engagement scale (Schaufeli \& Bakker, 2003), employee voice scale (Van Dyne \& Le Pine, 1998) and perceived insider status scale (Stamper \& Masterson, 2002) were used to measure the research variables. The data obtained from the sample were analyzed using the structural equation model and SPSS 23.0 and AMOS 22.0 package programs.
\end{abstract}

\footnotetext{
* Sorumlu Yazar: Selçuk Üniversitesi, İktisadi ve İdari Bilimler Fakültesi, İşletme Bölümü, Konya, Türkiye, ORCID: 0000-0001-8513-9842, mehtapfindik@selcuk.edu.tr.
} 
As a result of the research, it has been determined that perceived insider status and employee voice have a positive and statistically significant relations with job engagement. Similarly, perceived insider status has a positive and statistically significant effect on employee voice. In addition, it was concluded that the employee voice has a partial mediating role in the relationship between perceived insider status and job engagement. Just as the employees increase level of perception of insider status by participating in organizational practices, so too voice behaviors will increase and as a result of this, employees will engage in role indicates.

Keywords: Job Engagement, Perceived Insider Status, Employee Voice.

\section{Giriş}

Pozitif örgütsel davranış konularından biri olan işe angaje olma (engagement) kavramı (Özkalp ve Meydan, 2015: 5) yönetim literatüründe ilgi gören bir kavram olmakla birlikte, özellikle Türk yazınında bu olgunun kavramsallaştırılmasında "işe tutkunluk" (Bektaş ve Karagöz, 2018; Gencer ve Ayyıldız, 2018), "işe cezbolma” (Özer vd., 2015), "çalışmaya tutkunluk" (Turgut, 2011), "işe adanmışlık" (Bostancı ve Ekiyor, 2015; İnce, 2016), "örgütsel adanmışlı" (Altunay, 2017), "işe angaje olma" (Özkalp ve Meydan, 2015; Kodaş, 2018; Uyar ve Güzel, 2019) gibi farklı tanımlamaların olması hala kavramsallaştırma konusunda yazında tutarlılıklar bulunmadığını göstermektedir. Bu nedenle hem kavramsal hem de ampirik olarak işe angaje olma konusunda araştırmacılar arasında belirsizlik devam etmektedir (Dalal vd., 2008: 52). Christian vd. (2011: 90) bu belirsizliğinin nedenini kavramın hem bir kişilik özelliği hem de durumsal bir faktör olarak iki farklı görüş tarafından ele alınmasından kaynaklandığını belirtmektedir. Bu ikilik, kavramı kişilik özelliği olarak ele alan görüşün bireyler arasındaki farklılıklara (bireyler arası farkl11ıklar veya sadece bireysel farklılıklar) odaklanma eğiliminde olmasından, işe angaje olmayı durumsal bir faktör olarak ele alan görüşün ise belirli bir bireyin zaman içindeki farklılıklarına odaklanma eğiliminden kaynaklanmaktadır (Dalal vd., 2008: 52). Macey ve Schneider (2008: 6) kavramın kişilik özelliği (işe karşı pozitif görüşleri içermesi), durumsal (iş tatmini, işe katılım, bağll1ık ve personel güçlendirme gibi) ve davranışsal (örgütsel vatandaşlık davranışı gibi ekstra rol davranışları) olarak farklı yönlerinin var olmasının nedenini aslında kavramın örgütsel, bireysel ve gruplar arası farklı düzeylerde incelenmesinden kaynaklandığını belirtmiş̧ir. Bu noktada Kahn'ın (1990) da belirttiği gibi angaje olma bilişsel, duygusal ve davranışsal özellikleri kapsayan psikolojik bir durumdur. Bakker ve Schaufeli (2015) de işe angaje olmayı, adanmışlık, dinçlik, özveri ve özümseme ile karakterize edilen pozitif, tatmin edici, işle ilgili bir durum olarak tanımlamaktadır. İșe angaje olma tanımında kullanılan dinçlik, bireyin çalışırken yüksek düzeyde enerji ve zihinsel esnekliğe sahip olmasını ifade eder. Adanmışlık, çalışanın işine güçlü bir şekilde dahil olması ve önem, coşku ve meydan okuma hisleri ile iş deneyimini yaşaması anlamına gelir. Özümseme ise, çalışanın işine tamamen konsantre olması ve mutlu bir şekilde işe dahil olması ile karakterize edilir, böylece çalışanlar iş yerinde zamanın nasıl geçtiğini anlamazlar ve işten ayırmakta zorluk çekmektedirler (Bakker ve Demerouti, 2008: 209-210).

Örgüt üyesinin rol performansı sırasında diğer bir ifade ile örgüt tarafından kişiye verilen rol gereklerini yerine getirirken, fiziksel, bilişsel, duygusal ve zihinsel olarak bu role uyum sağlaması işe angaje olmayı ifade etmektedir (Kahn, 1990: 694). Dolayısıyla işe angaje olma, hem çalışan hem de örgüt açısından karşlıklı fayda sağlayan pro-sosyal örgütsel davranıştır (Macey ve Schneider, 2008). Bu nedenle işe angaje olmuş bir çalışan, işle ilgili hedeflere odakladığı, bilişsel olarak dikkatli olduğu, duygusal ve sosyal olarak işine bağlı olduğu için daha yüksek bir performans gösterebilmektedir (Alfes vd., 2013: 844). Bu yönüyle bu kavram, bireylerin rol performansını ne ölçüde ve nasıl iyileştirebildiğini ifade eden entelektüel angaje olma, çalışanın işiyle ilgili pozitif duygusal bağ hissetmesi olarak duygusal angaje olma ve çalışanların işle ilgili iyileştirmeler ve değişim hakkında meslektaşları ile konuşma düzeyi olarak ele alınan sosyal angaje olma şeklinde üç türde de ele alınmaktadır (Rees vd., 2013: 2783). Ayrıca işe angaje olma kavramı literatürde yaygın olarak iki görüş etrafında da şekillenmektedir (Schaufeli vd., 2008; Schaufeli vd., 2009; Xanthopoulou vd., 2009; Hakanen ve Schaufeli, 2012). Maslach ve Leiter'in (2008) çalışmalarını temel alan (örn., Leiter ve Maslach, 2005; Leiter ve Maslach, 1998; Maslach ve Goldberg, 1998) ilk görüş, işe angaje olmayı tükenmişlik kavramının zıttı olan bir olgu olarak değerlendirmekte, çalışanın yüksek düzeyde enerji ve özdeşleşmesi işe angaje olma; buna karş̧ı çalışanın düşük düzeyde özdeşleşmesi ise tükenmişlik olarak ifade edilmektedir (Du Plooy ve Roodt, 2010: 1). Bununla birlikte tükenmişlik temelli işe angaje olma kavramı tanımlanırken, tükenmişlik ve işe angaje olmanın çalışanın işle ilgili tutumlarının iki ucunu temsil ettiğini de belirtilmektedir. Tükenmişlik çalışanın duygusal tükenme, motivasyon kaybı ve başarı hissinin azalması ile işle ilgili kalıcı, negatif bir düşünceye kapılması olarak ele alınırken, işe angaje olma da anlık ve spesifik bir durum olmaktan ziyade adanmışlık, dinçlik, özveri ve özümseme ile ilişkili kalıcı ve yaygın bir duygusal-bilişsel durum olarak tanımlanır (Denton vd., 2008: 1). Ancak Kahn'ın (1990) çalışmalarını temel alan görüş işe angaje olma kavramını, tükenmişlikten bağımsız bir kavram olarak ele almakta ve bu noktada kavram Maslach Tükenme Envanteri'den (Maslach vd., 1986) ziyade örgütlerde farklı ölçüm ve kavramsallaştırmaları bulunan bir olgu haline gelmektedir (Özkalp ve Meydan, 2015: 56). Özellikle Schaufeli vd. (2002) çalışmalarını temel alan ve sonrasında Schaufeli vd. (2006) çalışmalarıyla tükenmişlik kavramına alternatif bir bakış açısı sunan işe angaje olma adanmışlık, dinçlik ve özümseme olarak üç boyutlu bir yapı halinde açıklanmıştır. Bu bakış açısından hareketle, işini daha fazla özümseyen çalışanların, hem örgütün hem de kendilerinin yararına olumlu ve işbirlikçi davranışlarda bulunma olasılıklarının daha yüksek olduğu belirtilmiştir (Rees vd., 2013).

Çalışanların hem kendi yararına hem de örgütün iyiliğine yönelik karşılıklılık ilişkisi temelinde ele alınan bu olgular yazında Sosyal Mübadele Teorisi (Blau, 1964; Emerson, 1976) ile açıklanmaktadır. Sosyal mübadele teorisi çerçevesinde işe angaje olma bireysel düzeyde bir yapı olarak düşünülmektedir. Dolayısıyla çalışanların örgülerine karşı olumlu sonuçlar elde edebilmesi için önce bireysel düzeyde sonuçlara ulaşması gerekmektedir (Karanges, 2014: 45). Çalışanın rol gerekleriyle ilişkili fazla miktarda bilişsel, duygusal ve fiziksel kaynağa sahip olması çalışanın bireysel olarak daha fazla rol performansı göstermesine neden olur. Bu nedenle bir çalışanın rol performansına ayırmaya hazırlandığı bilişsel, duygusal ve fiziksel kaynakların miktarı, örgütün çalışana tahsis ettiği ekonomik ve sosyoduygusal kaynaklara bağlıdır. Bu karşıllıklılık ilişkisi sonucunda çalışana örgütten ne kadar fazla ekonomik, sosyo-duygusal kaynak sağlanırsa çalışanda o derece örgütüyle ve işine karşı angaje olacaktır (Saks, 2006: 602-603). 
Bu doğrultuda çalışanın işe angaje olmasının hem çalışan hem de örgütsel açıdan birçok faydası ve yararı olacağı açıktır. Demerouti vd. (2001) iş talepleri-kaynakları modelinde iş taleplerinin işe angaje olmanın önemli bir öncülü olduğunu belirtmiştir. İş talepleri modeli, iş çevresinin fizyolojik ve psikolojik maliyetleri olan çalışan çabalarını gerektiren iş taleplerine çalışanların hedeflerine ulaşmalarına ve yardımcı olan iş kaynaklarının örgüt içerisinde nasıl dağıtılacağına odaklanır (Bakker ve Demerouti, 2007). İş talepleri, işin sürekli fiziksel ve/veya psikolojik çaba gerektiren fiziksel, psikolojik, sosyal veya örgütsel yönleri olarak tanımlanır ve belirli fizyolojik ve/veya psikolojik maliyetlerle ilişkilidir. Bu nedenle yenilikçilik ve beceri çeşitliliği gibi iş kaynakları yüksek olduğunda, iş̧ talepleri işe angaje olmanın bir öncülü olarak kabul edilir (Bakker ve Demerouti, 2017: 275). İşe angaje olmanın bu noktada önemli bir öncülü ise çalışan sesliliğidir. Özellikle iş taleplerinin karşılanmasında ve örgütsel iletişimin iki yönü olarak ifade edilebilecek örgütsel bilgi paylaşımı ve geri besleme mekanizmalarında örgüt içi iletişimin kaynağı çalışan sesliliğidir (Rothmann, 2014; Ruck vd., 2017). Van Dyne vd. (2003) çalışan sesliliğinin; çalışanların proaktif olarak değişim için önerilerde bulunduğu gibi konuşma davranışlarını ve örgütsel adalet kararlarını geliştiren ve çalışanların karar alma sürecine katılımını kolaylaştıran gerekli süreç prosedürlerinin varlığını tanımlayan ses davranışı olarak literatürde iki tanımının bulunduğunu ifade etmişlerdir. Çalışan sesliliği, örgüt içinde bilgi alan, danışılan veya ortak karar alma sürecinin bir parçası olan çalışanları ifade eder (Wood ve Fenton-O'Creevy, 2005). Çalışan sesliliği örgütsel ve örgütsel birimlerin işlevlerini geliştirmek amacıyla işle ilgili konulardaki fikir, öneri, endişe veya ilginin kasıtll olarak ifade edilmesi sonucu ortaya çıkan örgütsel bir iletişim şeklidir. Çalışan sesliliği doğrudan ve dolaylı bir şekilde gerçekleştirilebileceği gibi, özellikle örgütsel davranış yazını kapsamında doğrudan iletişim şekillerini ifade eden seslilik esas alınmaktadır (Kaufman, 2015: 20). Doğrudan iletişim olarak ele alınan çalışan sesliliği, çalışanların ses uygulamaları konusundaki bireysel deneyimlerini yöneticileri veya amirleri ile paylaşmasının ve bu paylaşımdaki etkileşimin kalitesi sonucu ortaya çıkmaktadır. Bu nedenle, liderin veya yöneticinin rolünün doğrudan çalışan sesliliğine etkisi dolaylı iletişimden daha büyük bir rol oynamaktadır. Doğrudan veya bireysel düzeyde bir bakış açısıyla, çalışan sesliliği özellikle iş talepleri gibi işle ilgili süreçlerde çalışanların örgütün karar alma sürecine dahil olmaları için firsatlar yaratan örgütsel uygulamaları ifade eder (Kwon vd., 2016: 328). Morrison'un (2011) da ifade ettiği gibi hem bireysel (iş talepleri, rol gerekleri, kişilik, iş performansı gibi) hem de kavramsal veya örgütsel (örgüt yapısı, örgüt kültürü, liderlik tarzları gibi) düzeydeki uygulamalar çalışanların sesliliğine maliyet veya etkinlik düzeyinde etkide bulunarak, örgütsel veya bireysel iş sonuçlarını etkilemektedir. Özellikle çalışanın iş talepleri ve çalışan performansı gibi bireysel düzeyde görülen çalışan sesliliğinin örgütsel sonuçları çalışanın işe angaje olmasında önemli bir öncül olarak ele alınır (Rees vd., 2013; Cheng vd., 2013; Cheng vd., 2014; Milliken vd., 2015; Kwon vd., 2016, Ruck vd., 2017; Amah ve Sese, 2018). Çalışanın sosyal değişim mekanizmaları çerçevesinde, örgütsel iletişim düzeylerine katılmaları ve özellikle çalışanın kendi iş gerekleri konusunda örgüt tarafından sesliliğin desteklenmesi çalışanların daha yüksek düzeyde işe katılmlarını sağlayarak hem performaslarını hem de işe angaje olma düzeylerini artıracaktır (Amah ve Sese, 2018). $\mathrm{Bu}$ doğrultuda, araştırmanın birinci hipotezi aşağıdaki şekilde oluşturulmuştur.

\section{$\mathrm{H}_{1}$ : Çalışanların işe angaje olma düzeylerinin çalışan sesliliği üzerinde pozitif yönlü bir etkisi vardır.}

Sosyal mübadele teorisi çerçevesinde değerlendirilen bir diğer konu ise algılanan içsellik statüsüdür (Kanbur ve Kanbur, 2015: 198). Örgüt içinde çalışmaya devam edenler (insider) ve örgüte yeni ve dışarıdan gelenler (outsider) arasındaki ayrımı esas alan algılanan içsellik statüsü, belirli çalışanların örgütü içselleştirme süreçlerini teşvik etmek amacıyla eğitim ve promosyonlar gibi teşvikleri kullanmasının bir sonucudur. Bu teşvikler sonucunda çalışanında örgüte katılım düzeyi artmaktadır (Stamper ve Masterson, 2002: 877). İçsellik statüsü algısı, örgütsel sosyalizasyon sürecinin bir kombinasyonu olarak çalışanların grup içi üye statüsüne ulaştıklarını hissetmesiyle gelişmektedir. Bu algıyı yüksek düzeyde hisseden çalışanlar kendilerini örgütün merkezi ve önemli bir parçası olarak algılarlar, yüksek düzeyde örgütsel katılım gösterirler (Knapp vd., 2014: 274-275). Yüksek düzeyde içsellik statüsüne sahip çalışanlar kendilerini örgütün üyeleri olarak tanımlar, örgüte aidiyet geliştirirler (Ding ve Shen, 2017), örgütün değerleri ve hedefleri ile kendilerini özdeşleşirler ve bu yönde hareket ederler. Bu çalışanların örgütte kalma niyetleri de yüksektir. Algılanan içsellik statüsü düşük olan çalışanlar ise (kendilerini örgüte yabancılaşmış hissedenler) örgüte yüksek düzeyde katılımdan ziyade kopma ve reddetme duygularına sahip olacaklardır (Ouyang vd., 2015). Bu doğrultuda, araştırmanın ikinci hipotezi aşağıdaki şekilde oluşturulmuştur.

\section{$\mathrm{H}_{2}$ : Çalışanların işe angaje olma düzeylerinin algılanan içsellik statüsü üzerinde pozitif yönlü bir etkisi vardır.}

Örgütsel aidiyetin veya bir nevi sosyalizasyon sürecinin gelişiminde içsellik statüsü Katz ve Kahn'ın (1966) belirttiği gibi, grup içerinde grup üyelerinin birbirlerini grup içi ve grup dışı olarak ayırmasının bir sonucudur. Kendini grup içi olarak hisseden çalışanlar, diğer çalışanları içselleştirme ve onlarla samimi olma açısından örgütün sosyal sınırlarına hakim oldukları için grup dışı üyelere göre örgüt içerisinde daha fazla kişisel alan yaratabilmektedirler (Lapalme vd., 2009: 921). Çalışan tarafından örgüt içerisinde yaratılan bu kişisel alan, çalışanın ihtiyaç ve duygularını diğer grup içi üyelerle paylaşmakta özgür olduğu inancını sağlayarak, çalışanın örgüt içerisinde statü elde etmesine neden olur (Zhu vd., 2019) ve çalışanların örgüte kabulünü kolaylaştırır (Horng vd., 2016: 57). Algılanan içsellik statüsünün, lider üye etkileşimi (Stamper ve Masterson, 2002) ve bu etkileşimin kalitesi (Kassing, 2000), katılmalı yönetim algısı (Hui vd., 2015), örgütsel destek algısı (Lapalme vd., 2009), iş-aile uyumu (Choi vd., 2018), benlik algısı (Dai ve Chen, 2015), istismarcı yönetim (Ouyang vd., 2015) gibi literatürde birçok öncülü bulunmaktadır. Bununla birlikte genellikle bir sosyalizasyon süreci olarak değerlendirilen içsellik statüsünün örgütsel sapma, örgütsel vatandaşlık davranışı (Khan vd., 2019), örgütsel özdeşleşme (Stamper ve Masterson, 2002), çalışan performansı (Xiao, 2015) gibi örgütsel sonuçlar üzerinde de etkisi bulunmaktadır. Aynı zamanda algılanan içsellik statüsü, örgütte proaktif davranışların ortaya çıkmasına neden olarak, çalışan sesliliği (Li vd., 2014; Ouyang vd., 2015) ve işe angaje olmanın (Dai ve Chen, 2015) örgüt içerisinde yayılımına neden olmaktadır. Bu doğrultuda, içsellik statüsü yüksek olan çalışanların örgüt içerisinde diğer çalışanlarla ve örgütle iletişim düzeyinin yüksek olacağı düşüncesiyle, çalsşan sesliliği davranışlarının artacağı, örgüt içi gruplara ve örgüte yönelik aidiyet hissetmesi nedeniyle de örgütüyle daha çok bütünleşeceği ve işe angaje olma düzeylerinin de artacağı düşünülmektedir. Bu noktada, literatürde ileri sürülen bilgiler ışı̆̆ında, araştırmanın diğer hipotezleri aşağıdaki şekilde belirlenmiştir.

$\mathrm{H}_{3}$ : Algılanan içsellik statüsünün çalışan sesliliği üzerinde pozitif yönlü bir etkisi vardır. 
$\mathrm{H}_{4}$ : Çalışanların işe angaje olma düzeyleri ile algılanan içsellik statüsü arasındaki ilişkide çalışan sesliliğinin aracılık rolü vardır.

\section{Araştırma Metodolojisi}

Nicel araştırma yöntemi benimsenen bu araştırmada verilerin analizinde için öncelikle ölçüm modeli (doğrulayıcı faktör analizi) test edilmiş ve yapısal model geliştirilerek, bu modellerin analizlerinde SPSS 23.0 ve AMOS 22 programı kullanılmıştır. Araş̧ırmanın evrenini Konya'da bilişim sektörü çalışanları oluşturmaktadır. Bilişim sektöründe çalışanlara iliş̧kin evren büyüklüğü net olarak tahmin edilememekle birlikte +-0.05 örnekleme hatasında 384 kişilik bir örneklemin 100000 kişilik evreni temsil yeteneğine sahip olduğunu belirtmiştir (Öztürk ve Çoban, 2019: 248). Bu doğrultuda, araştırmada bilişim sektöründe 403 çalışandan oluşan örneklem basit tesadüfi örnekleme yöntemi ile seçilmiştir. Anket verileri Kasım-Aralık 2019 tarihleri arasında katılımcılardan online olarak toplanmıştır. Ankete katılan çalışanların büyük bir kısmının erkek (\%66), 30-40 yaş arası (\%45), üniversite mezunu (\%38) olduğu ve 5 yıldan uzun süredir (\%72) bilişim sektöründe çalıştıkları tespit edilmiştir. Araştırma değişkenlerine ilişkin kullanılan ölçekler aşağıda belirtilmiştir.

- Işse Angaje Olma: Schaufeli ve Bakker (2003) tarafından geliştirilen, Türkçe geçerlilik ve güvenilirlik çalışması Özkalp ve Meydan (2015) tarafından yapılan işe angaje olma ölçeğinin kısa formu kullanılmıştır. Ölçek; dinçlik (3 ifade), adanmışlık ( 3 ifade) ve özümseme ( 3 ifade) olmak üzere 3 boyuttan ve 9 maddeden oluşmaktadır.

- Çalışan Sesliliği: Van Dyne ve Le Pine (1998) tarafindan geliştirilen, Çetin ve Çakmakçı (2012) tarafından Türkçe geçerlilik ve güvenilirlik çalışması yapılan çalışan sesliliği ölçeği, Van Dyne ve Le Pine'in (1998) çalışmasına uygun olarak 6 ifadeden oluşmaktadır.

- Algılanan İçsellik Statüsü: Akdoğan ve Köksal (2014), Mirap (2008) çalışmalarında kullandıkları ve Stamper ve Masterson (2002) tarafından geliştirilen 6 ifadeden oluşan algılanan içsellik statüsü ölçeğinden yararlanılmıştır.

\section{Araştırma Sonuçları}

Araştırmada kullanılan ölçeklerin geçerlilik analizini test etmek amacıyla doğrulayıcı faktör analizi yapılmıştır. Her bir değişkene ilişsin en iyi uyum değerlerine sahip doğrulayıcı faktör analizi sonuçları Tablo 1'de verilmiştir.

Tablo 1. Ölçeklerin Uyum Iyiliği Değerleri

\begin{tabular}{l|c|c|c|c|c|c}
\hline Değişken & $\mathbf{X}^{\mathbf{2}}$ & $\mathbf{d f}$ & $\mathbf{X}^{\mathbf{2}} / \mathbf{d f}$ & $\mathbf{G F I}$ & $\mathbf{C F I}$ & $\mathbf{R M S E A}$ \\
\hline Algılanan İçsellik Statüsü & 0.784 & 2 & 0.392 & 0.999 & 1.000 & 0.000 \\
\hline Çalışan Sesliliği & 1.714 & 2 & 0.857 & 0.998 & 1.000 & 0.000 \\
\hline İşe Angaje Olma & 61.135 & 24 & 2.547 & 0.967 & 0.977 & 0.062 \\
\hline İyi Uyum Değerleri & & & $\leq 3$ & $\geq 0.90$ & $\geq 0.95$ & $\leq 0.05$ \\
\hline Kabul Edilebilir Uyum Değerleri & & & $\leq 4-5$ & $\geq 0.85$ & $\geq 0.90$ & $\leq 0.08$ \\
\hline
\end{tabular}

Araştırmada kullanılan her bir ölçeğin yapı geçerliliği için ayrı ayrı doğrulayıcı faktör analizi kullanılmış kabul edilebilir uyum iyiliği değerleri için ölçekten ifadeler çıkartılarak tekrar modifikasyonlar yapılmıştır. Algılanan içsellik statüsü 4 ifade, çalışan sesliliği için 4 ifade ve işe angaje olma ölçeği için 9 ifadenin doğrulayıcı faktör analizi sonucunda uyum iyiliği değerlerinin kabul edilebilir sınırlar içerisinde ve anlamlı $(\mathrm{p}<.05)$ olduğu tespit edilmiştir. Araştırma değişkenleri arasındaki ilişkiler korelasyon analizi ile araştırılmıştır. Değişkenlere ilişkin pearson korelasyon, ortalama, standart sapma ve güvenilirlik analizi (cronbach alpha) sonuçları Tablo 2'de yer almaktadır.

Tablo 2. Değişkenlere Ait Ortalama, Standart Sapma, Güvenilirlik ve Korelasyon Değerleri

\begin{tabular}{l|c|c|c|c|c}
\hline Değişkenler & $\overline{\mathbf{X}}$ & SD & $\mathbf{1}$ & $\mathbf{2}$ & $\mathbf{3}$ \\
\hline Algılanan İçsellik Statüsü (1) & 3.99 & 0.69 & $(0.643)$ & & \\
\hline Çalışan Sesliliği (2) & 3.18 & 0.97 & $.229^{* *}$ & $(0.854)$ & \\
\hline İşe Angaje Olma (3) & 2.97 & 0.80 & $.225^{* *}$ & $.555^{* *}$ & $(0.868)$ \\
\hline
\end{tabular}

Not: $\mathrm{n}=403 ;{ }^{*} \mathrm{p}<.001,{ }^{*} \mathrm{p}<.05$.

Araştırma değişkenlerine ait ölçeklerin Cronbach’s Alpha $(\alpha)$ değerlerinin incelendiğinde yüksek düzeyde güvenilir olduğu sonucuna ulaşılmıştır $(0.60>\alpha>0.80)$. Araştırmada esas alınan her bir değişkenin ortalama ve standart sapma değerleri incelendiğinde ise ankete katılan katılımcıların çalışan sesliliği ve işe angaje olma ifadelerine orta düzeyde katıldıkları ve içsellik statüsü algılarının ise yüksek olduğu ifade edilebilir. Ayrıca korelasyon analizi sonuçları değerlendirildiğinde, algıllanan içsellik statüsü ve çalışan sesliliği $(\mathrm{r}=.229, \mathrm{p}<.05)$ ile işe angaje olma $(\mathrm{r}=.225, \mathrm{p}<.05)$ arasında pozitif yönlü ve anlamlı bir ilişki olduğu tespit edilmiştir. İşe angaje olma ile çalışan sesliliği arasında $(\mathrm{r}=.555, \mathrm{p}<.05)$ orta düzeyde, pozitif yönlü ve anlamlı bir ilişki olduğu tespit edilmiştir. Araştırmada ileri sürülen hipotezleri test edebilmek amacıyla yapısal eşitlik modeli kullanılmış ve analiz sonuçları Tablo 3 'de gösterilmiştir.

\section{Tablo 3. Yapısal Eşitlik Modeli Uyum Iyiliği Değerleri}

\begin{tabular}{l|c|c|c|c|c|c}
\hline Değişken & $\mathbf{X}^{\mathbf{2}}$ & $\mathbf{d f}$ & $\mathbf{X}^{\mathbf{2}} / \mathbf{d f}$ & GFI & CFI & RMSEA \\
\hline Algılanan İçsellik Statüsü - İşe Angaje Olma & 211.295 & 61 & 3.464 & 0.928 & 0.926 & 0.078 \\
\hline Çalış̧an Sesliliği - İşe Angaje Olma & 145.732 & 61 & 2.389 & 0.944 & 0.967 & 0.059 \\
\hline
\end{tabular}




\begin{tabular}{l|c|c|c|c|c|c}
\hline Algılanan İçsellik Statüsü - Çalışan Sesliliği & 11.353 & 13 & 0.873 & 0.992 & 1.000 & 0.000 \\
\hline İyi Uyum Değerleri & & & $\leq 3$ & $\geq 0.90$ & $\geq 0.95$ & $\leq 0.05$ \\
\hline Kabul Edilebilir Uyum Değerleri & & & $\leq 4-5$ & $\geq 0.85$ & $\geq 0.90$ & $\leq 0.08$ \\
\hline
\end{tabular}

Tablo 3'de yer alan kabul edilebilir uyum indeksleriyle karşılaştırıldığında modelin yeterli uyumu sağladığ1 görülebilmektedir. Yapısal olarak doğrulanan bu model incelendiğinde; 3 boyutlu yapı olarak ele alınan işe angaje olmanın algılanan içsellik statüsü ve çalışan sesliliği ile arasında istatistiksel bakımdan anlamlı ilişki olduğu tespit edilmiştir. Ayrıca algılanan içsellik statüsü ve çalışan sesliliği arasında da istatistiksel bakımdan anlamlı ilişki olduğu görülmektedir. Yapısal eşitlik modeline ilişkin katsayılar ise Tablo 4 'te yer almaktadır.

Tablo 4. Yapısal Eşitlik Modeli Katsayıları

\begin{tabular}{l|c|c|c|c}
\hline Değişkenler & Standardize $\boldsymbol{\beta}$ & Standart Hata & p & $\mathbf{R}^{2}$ \\
\hline Algılanan İçsellik Statüsü - İşe Angaje Olma & 0.080 & 0.056 & $* * *$ & 0.010 \\
\hline Çalışan Sesliliğgi - İşe Angaje Olma & 0.670 & 0.103 & $* * *$ & 0.450 \\
\hline Algılanan İçsellik Statüsü - Çalışan Sesliliği & 0.100 & 0.057 & $* * *$ & 0.010 \\
\hline
\end{tabular}

Yapısal eşitlik modelinin katsayılar tablosuna göre, algılanan içsellik statüsü ve işe angaje olma arasında pozitif yönlü ve istatistiksel bakımdan anlamı bir ilişki olduğu $(\beta=0.08 ; p<.05)$, bağımsız değişken olan algılanan içsellik statüsünün bağımlı değişken olan işe angaje olmanın \%1'ini açıkladığı sonucuna ulaşılmıştır. Model kapsamında elde edilen bir diğer sonuç ise işe angaje olma ve çalışan sesliliği arasında da pozitif yönlü ve istatistiksel bakımdan anlamı bir ilişki olduğu $(\beta=0.67$; $<<.05)$, çalışan sesliliğinin işe angaje olmanın \%45'ini açıkladığı tespit edilmiştir. Algılanan içsellik statüsü ve çalışan sesliliği arasındaki ilişki incelendiğinde ise, benzer şekilde pozitif yönlü ve istatistiksel bakımdan anlamı bir ilişki olduğu $(\beta=0.10 ; p<.05)$ ve çalışanların seslilik düzeylerinin $\% 1$ 'lik kısmının içsellik statüsü algısı ile açıklanabildiği görülmektedir. Bu doğrultuda, araştırmanın H1, H2 ve H3 hipotezleri desteklenmektedir. AMOS 22.0 istatistik programı kullanılarak analiz edilen yapısal eşitlik modelinin sonuçları ise Şekil 1'de sunulmuştur.

\section{Şekil 1. Yapısal Eşittik Modeli Sonuçları}

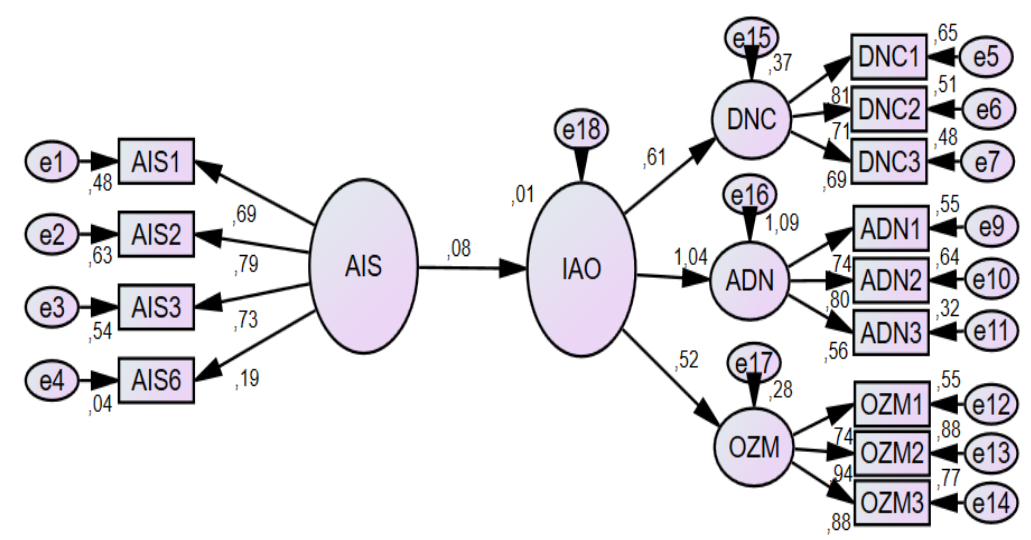

Not: Şekilde yer alan değerler standartlaştııılmış regresyon katsayılarııı (Standardized Estimates) göstermektedir ( $\mathrm{p}<0.05)$.

Araştırma kapsamında aracılık etkisini ölçümlemek amacıyla geliştirilen H4 hipotezini tespit etmek için yapısal eşitlik modellemesinden yararlanılmış ve analiz sonuçları Tablo 5 'te gösterilmiştir.

Tablo 5. Aracılık Etkisini Ölçmek İçin Oluşturulan Yapısal Eşitlik Modelinin Uyum İyiliği Değerleri

\begin{tabular}{l|c|c|c|c|c|c}
\hline Değişken & $\mathbf{X}^{\mathbf{2}}$ & $\mathbf{d f}$ & $\mathbf{X}^{\mathbf{2}} / \mathbf{d f}$ & $\mathbf{G F I}$ & $\mathbf{C F I}$ & $\mathbf{R M S E A}$ \\
\hline $\begin{array}{l}\text { Algilanan İçsellik Statüsü - Çalışan Sesliliği } \\
\text { - Isşe Angaje Olma }\end{array}$ & 323.833 & $\begin{array}{c}11 \\
3\end{array}$ & 2.866 & 0.913 & 0.930 & 0.068 \\
\hline Iyi Uyum Değerleri & & & $\leq 3$ & $\geq 0.90$ & $\geq 0.95$ & $\leq 0.05$ \\
\hline Kabul Edilebilir Uyum Değerleri & & & $\leq 4-5$ & $\geq 0.85$ & $\geq 0.90$ & $\leq 0.08$ \\
\hline
\end{tabular}

Tablo 5'teki veriler, algılanan içsellik statüsü le işe angaje olma rasındaki ilişkide çalışan sesliliğinin aracı rolünü incelemek amacıyla oluşturulan modelin uyum değerlerinin kabul edilebilir sınırlar içinde olduğunu ve modelin yapısal olarak uygun olduğuna ilişkin yeterli kanıtları sağlamaktadır. Yapısal eşitlik modeline ilişkin katsayılar Tablo 6'da yer almaktadır.

Tablo 6. Aracılık Etkisini Ölçmek İçin Oluşturulan Yapısal Eşitlik Modeli Katsayıları

\begin{tabular}{l|c|c|c|c}
\hline Değişkenler & Standardize $\boldsymbol{\beta}$ & Standart Hata & $\mathbf{p}$ & $\mathbf{R}^{\mathbf{2}}$ \\
\hline Algılanan İçsellik Statüsü - İşe Angaje Olma & 0.04 & 0.067 & $* * *$ & \multirow{2}{*}{0.46} \\
\hline Çalışan Sesliliği - İşe Angaje Olma & 0.67 & 0.103 & $* * *$ & \\
\hline Algılanan İçsellik Statüsü - Çalışan Sesliliği & 0.12 & 0.058 & $* * *$ & 0.01 \\
\hline
\end{tabular}


Baron ve Kenny (1986) tarafindan önerilen aracılık etkisi modeli kapsamında aracılık etkisini tespit edilebilmesi, algıllanan içsellik statüsü, çalışan sesliliği ve işe angaje olma arasındaki ilişkiler incelenmiştir. Açıklayıcı değişkenler olan algılanan içsellik statüsü ve çalışan sesliliğinin bağımlı değişken olan işe angaje olma davranışı algısının varyansının \% 46'sını açıkladığı görülmektedir $\left(\mathrm{R}^{2}=0.46\right)$. Çalışan sesliliğinin algılanan içsellik statüsü ve işe angaje olma arasındaki ilişkiye dahil edilmesiyle algılanan içsellik statüsünün işe angaje olma üzerindeki etkisi $\beta=0.08$ 'den $\beta=0.04$ 'e düşmekte, $\mathrm{R}^{2}=0.01$ 'den $\mathrm{R}^{2}=0.46$ 'ya artış göstermekte ve modelinin açıklayıcıllğ 1 artmaktadır. Çalışan sesliliği modele eklendikten sonra içsellik statüsü algısının etkisinin azalması ve bu etkinin anlamlı olması (p>.05), algılanan içsellik statüsü ve işe angaje olma arasındaki ilişkide çalışan sesliliğinin kısmi aracılık rolüne sahip bir değişken olduğunu göstermektedir. Bulunan aracılık etkisinin anlamlılığını tespit etmeye yönelik olarak Sobel testi yapılmıştır. Sobel analizi sonucunda $z$ değeri 2.26 olarak hesaplanmış olup, $\mathrm{z}$ değeri istatistiksel bakımdan anlamlıdır $(\mathrm{p}<.01)$. Bu veriler doğrultusunda araştırmanın 4 . hipotezi desteklenmiştir. Aracılık etkisine ilişkin yapısal eşitlik modeli analiz sonuçları Şekil 2'de gösterilmiştir.

\section{Şekil 2. Aracılık Analizi Sonuçları}

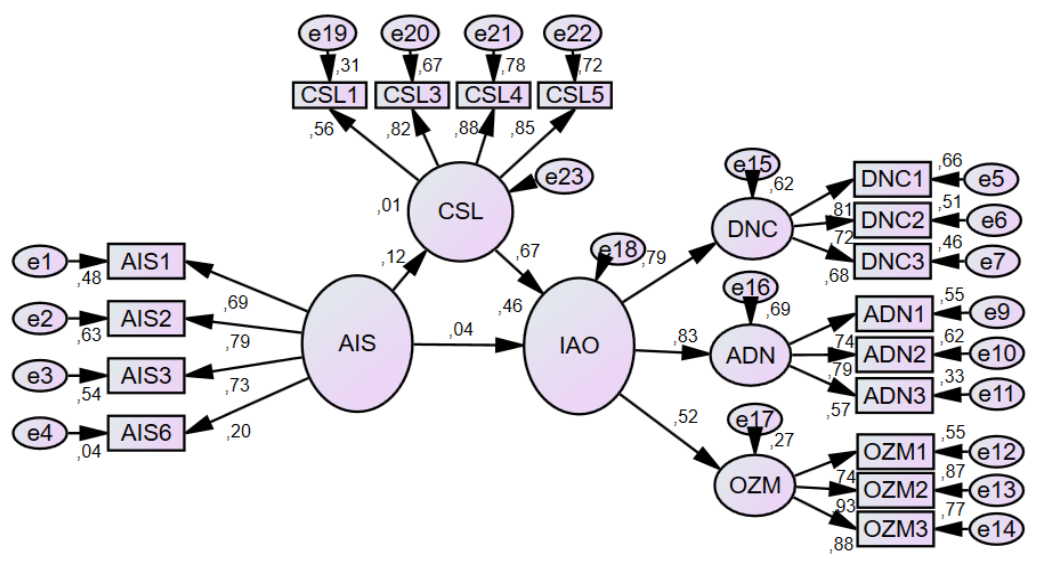

Not: Şekilde yer alan değerler standartlaştırılmış regresyon katsayılarını (Standardized Estimates) göstermektedir ( $\mathrm{p}<.05)$.

\section{Sonuç}

Bu çalışmanın amacı işe angaje olma, algılanan içsellik statüsü ve çalışan sesliliği arasındaki ilişkilerin incelenmesidir. Örgütsel davranış yazınında algılanan içsellik statüsünün çalışan sesliliği (Li vd., 2014; Ouyang vd., 2015) ve işe angaje olma (Dai ve Chen, 2015) ile arasında pozitif yönlü bir ilişki olduğu belirtilmektedir. Mevcut çalışmada elde edilen sonuç, yüksek düzeyde içsellik statüsü algısına sahip olan çalışanların neden daha yüksek düzeyde işe angaje olma davranışı gösterdiklerini açıklamaktadır. Ayrıca çalışmada bir diğer açıklayıcı değiş̧ken olan çalışan sesliliğinin, çalışanların işe angaje olma düzeylerini de etkilediği belirtilmektedir. Bu doğrultuda araştırmada literatüre benzer şekilde algılanan içsellik statüsünün çalışan sesliliği ve işe angaje olma ile olan ilişkisinin pozitif yönlü ve istatistiksel bakımdan anlamlı olduğu tespit edilmiştir. Ancak ilgili literatürde algılanan içsellik statüsünün işe angaje olma üzerindeki ilişkisinde çalışan sesliliğinin aracı rolünü inceleyen çalışmalara rastalanılamamıştır. Bu nedenle araştırma sonuçlarının özellikle aracılık ilişkisinin incelenmesi düzeyinde katkı sağlayacağı düşünülmektedir. Ayrıca Türkiye'de gelişmekte olan sektörlerden biri olan bilişim sektörünün takım çalışmasına yatkın bir örgütsel yapıya sahip örgütlerden oluşması, yine sektörün bilgi temelli bir sektör olması ve bu nedenle daha esnek örgütsel yapıya sahip olacağı düşüncesiyle araştırma kapsamında ele alınan değişkenler arasındaki ilişkinin bu sektörde çalışanlar üzerinde daha anlamlı sonuçlar vermesi beklenmiştir. Özellikle bilişim sektörü çalışanların örgütsel davranışlarının incelendiği çalışmaların Türk yazınında sınırlı olması (Kalay vd., 2009; Erkmen ve Esen, 2012; Alan ve Fidanboy, 2013; Örnek ve Ayas, 2015; Akturan vd., 2017; Fidanboy ve Fidanboy, 2018) nedeniyle de çalışmanın mevcut örgütsel davranış yazınına katkı sağlayacağı düşünülmektedir.

Ayrıca bu çalışmanın bazı sınırlılıkları bulunmaktadır. İlk olarak, çalışmada elde alınan konular çalışanların bir nevi kişilik veya psikolojik temelli özelliklerini yansıtacağı için, ele alınan ilişkiler zaman içerisinde değişebilmektedir. Bu nedenle çalışmanın farklı zaman dilimlerinde veya bilişim sektöründe bilginin yoğun olduğu ve bu bilgilerin zaman içerisinde örgüt içerisinde yayılım yollarının değişebileceği düşüncesiyle farklı sektörlerde incelenmesinde fayda bulunmaktadır. Çalışmanın ikinci sınırlılığı ise araştırma verilerinin analizinde AMOS programı kullanılmasıdır. AMOS ve LISREL gibi yapısal eşitlik modellemesine dayalı analiz yöntemleri kovaryans temelli yöntemler olup bu modellerin ölçülmesinde verilerin büyük örneklemler ile çalışılması ve normal (parametrik) dağılımının sağlanması gerekmektedir. Normal dağılım göstermeyen veriler ise bu analizler kapsamında değerlendirilememektedir. Bu nedenle gelecekte yapılacak çalışmalarda Smart PLS gibi farklı analiz yöntemlerinin kullanılmasında fayda görülmektedir. Araştırmanın bir diğer sınırlılı̆̆ı ise kullanılan ölçeklerdir. Bu çalı̧̧mada her ne kadar literatürde yaygın olarak kullanılan ölçeklere yer verilmeye çalışılsa da özellikle çalışan sesliliği ölçeğine ilişkin olarak kabullenici seslilik, savunmacı seslilik ve örgüt yararına seslilik olarak üç alt boyuttan oluşan ölçeğin de kullanıldığı (Şehitoğlu ve Zehir, 2010) bilinmektedir. Bu nedenle literatürde geliştirilen farklı ölçeklerin de kullanılarak çalışmanın sonuçlarııın tekrar incelenmesinde fayda bulunmaktadır. Ayrıca araştırmada incelenen değişkenlerden biri olan işe angaje olmanın genellikle yazında pozitif örgütsel davranış kapsamında ele alındığı bilinmektedir. Ancak yüksek düzeyde işe angaje olan çalışanların yabancılaşma, işte var olamama, tükenmişlik gibi negatif örgütsel sonuçlara sebebiyet vereceği de açıktır. Bu nedenle gelecekte yapılacak olan çalışmalarda özellikle işe angaje olma davranışlarının negatif öncül veya sonuçlarının çalışma kapsamına dahil edilerek incelenmesi önerilmektedir. 


\section{Kaynakça}

Akdoğan, A., \& Köksal, O. (2014). Aidiyet Algısının Örgütsel Vatandaşlık Davranışı Üzerindeki Etkisinde Yöneticiye Güvenin Aracılık Rolü. Journal of Graduate School of Social Sciences, 18(1),25-43.

Akturan, A., Günsel, A., \& Becerikli, M. (2017). Duygusal emek kavramı ve duygusal emeğin takım başarısı üzerindeki etkileri: bilişim sektörü çalışanları üzerinde bir uygulama. International Journal of Tourism, Economics and Business Sciences, 1(1), 34-47.

Alan, H. \& Fidanboy, C. Ö. (2013). Sinizm, tükenmişlik ve kişilik arasındaki ilişkiler: bilişim sektörü çalışanları kapsamında bir inceleme. Süleyman Demirel Üniversitesi Sosyal Bilimler Enstitüsü Dergisi, 1, 165-176.

Alfes, K., Truss, C., Soane, E. C., Rees, C., \& Gatenby, M. (2013). The relationship between line manager behavior, perceived HRM practices, and individual performance: Examining the mediating role of engagement. Human Resource Management, 52(6), 839859.

Altunay, E. (2017). İlköğretim okulu öğretmenlerinin örgütsel güven ve adanmışlık düzeyleri arasındaki ilişkinin incelenmesi. Milli Ĕ̈itim Dergisi, 46(213), 37-66.

Amah, O. E., \& Sese, E. (2018). Relational Energy \& Employee Engagement: Role of Employee Voice \& Organisational Support. Indian Journal of Industrial Relations, 53(3), 475-487.

Bakker, A. B., \& Demerouti, E. (2007). The job demands-resources model: State of the art. Journal of Managerial Psychology, 22, 309 $-328$.

Bakker, A. B., \& Demerouti, E. (2008). Towards a model of work engagement. Career Development International, 13 (3), 209-223.

Bakker, A. B., \& Demerouti, E. (2017). Job demands-resources theory: taking stock and looking forward. Journal of Occupational Health Psychology, 22(3), 273-285.

Bakker, A. B., \& Schaufeli, W. B. (2015). Work engagement. Wiley Encyclopedia of Management, 1-5.

Baron, R. M., ve Kenny, D. A. (1986). The moderator-mediator variable distinction in social psychological research: Conceptual, strategic, and statistical considerations. Journal of Personality and Social Psychology, 51(6), 1173-1182.

Bektaş, M., \& Karagöz, Ş. (2018). İzlenim yönetimi davranışının işe tutkunluğa etkisinde sosyal görünüş kaygısının aracılık rolü. Sosyal Araştırmalar ve Davranış Bilimleri Dergisi, 4(6), 275-299.

Blau, P. (1964). Exchange and power in social life. USA: John Wiley \& Sons.

Bostancı, H., \& Ekiyor, A. (2015). Çalışanların işe adanmasının örgüt içi girişimciliğe etkisinin incelenmesi. Uluslararası Sağllk Yönetimi ve Stratejileri Araştırma Dergisi, 1(1), 37-51.

Cheng, J. W., Chang, S. C., Kuo, J. H., \& Cheung, Y. H. (2014). Ethical leadership, work engagement, and voice behavior. Industrial Management \& Data Systems, 114(5), 817-831.

Cheng, J. W., Lu, K. M., Chang, Y. Y., \& Johnstone, S. (2013). Voice behavior and work engagement: the moderating role of supervisorattributed motives. Asia Pacific Journal of Human Resources, 51(1), 81-102.

Choi, J., Kim, A., Han, K., Ryu, S., Park, J. G., \& Kwon, B. (2018). Antecedents and consequences of satisfaction with work-family balance: A moderating role of perceived insider status. Journal of Organizational Behavior, 39(1), 1-11.

Christian, M. S., Garza, A. S., \& Slaughter, J. E. (2011). Work engagement: A quantitative review and test of its relations with task and contextual performance. Personnel Psychology, 64(1), 89-136.

Çetin, Ş., \& Çakmakçı, C. (2012). Çalışan sesliliği ölçeğini Türkçe'ye uyarlama çalışması. KHO Bilim Dergisi, 22(2), 1-19.

Dai, L., \& Chen, Y. (2015). A systematic review of perceived insider status. Journal of Human Resource and Sustainability Studies, 3(02), 66-72.

Dalal, R. S., Brummel, B. J., Wee, S., \& Thomas, L. L. (2008). Defining employee engagement for productive research and practice. Industrial and Organizational Psychology, 1(1), 52-55.

Demerouti, E., Bakker, A. B., Nachreiner, F., \& Schaufeli, W. B. (2001). The job demands resources model of burnout. Journal of Applied Psychology, 86, $499-512$.

Denton, D. A., Newton, J. T., \& Bower, E. J. (2008). Occupational burnout and work engagement: a national survey of dentists in the United Kingdom. British Dental Journal, 205(7), 1-8.

Ding, C. G., \& Shen, C. K. (2017). Perceived organizational support, participation in decision making, and perceived insider status for contract workers. Management Decision. 55 (2), 413-426.

Du Plooy, J., \& Roodt, G. (2010). Work engagement, burnout and related constructs as predictors of turnover intentions. SA Journal of Industrial Psychology, 36(1), 1-13.

Emerson, R. M. (1976). Social exchange theory. Annual Review of Sociology, 2(1), 335-362.

Erkmen, T., \& Esen, E. (2012). Bilişisim sektöründe çalışanların psikolojik sermaye düzeylerinin belirlenmesine yönelik bir araştırma. Afyon Kocatepe Üniversitesi İktisadi ve İdari Bilimler Fakültesi Dergisi, 14(2), 55-72.

Fidanboy, C. Ö., \& Fidanboy, M. (2018). Yenilik ikliminin örgütsel özdeşleşmeye etkisi: bilişim sektörü çalışanları üzerinde bir araştırma. Business \& Management Studies: An International Journal, 6(3), 362-378.

Gencer, K., \& Ayyıldız, T. (2018). Demografik özellikler ve psikolojik koşulların işe tutkunluğa etkisi: otel işletmeleri örneği. Manas Sosyal Araştirmalar Dergisi, 7(2), 601-619.

Guo, J., Qiu, Y., \& Gan, Y. (2020). Workplace Incivility and Work Engagement: The Chain Mediating Effects of Perceived Insider Status, Affective Organizational Commitment and Organizational Identification. Current Psychology, 1-12.

Hakanen, J. J., \& Schaufeli, W. B. (2012). Do burnout and work engagement predict depressive symptoms and life satisfaction? A threewave seven-year prospective study. Journal of Affective Disorders, 141(2-3), 415-424.

Horng, J. S., Tsai, C. Y., Hu, D. C., \& Liu, C. H. (2016). The role of perceived insider status in employee creativity: developing and testing a mediation and three-way interaction model. Asia Pacific Journal of Tourism Research, 21(1), 53-75. 
Hui, C., Lee, C., \& Wang, H. (2015). Organizational inducements and employee citizenship behavior: The mediating role of perceived insider status and the moderating role of collectivism. Human Resource Management, 54(3), 439-456.

İnce, A. R. (2016). Algılanan Örgütsel Desteğin İşe Adanmışlık Üzerindeki Etkisinde Yönetici Desteğinin Aracılık Rolü. Electronic Journal of Social Sciences, 15(57), 649-660.

Kahn, W. A. (1990). Psychological conditions of personal engagement and disengagement at work. Academy of Management Journal, 33(4), 692-724.

Kahn, W. A. (1990). Psychological conditions of personal engagement and disengagement at work. Academy of Management Journal, 33(4), 692-724.

Kalay, F., Şimşek, M., \& Oğrak, A. (2009). Bilişim teknolojilerinin iş stresi üzerindeki etkileri: türk bankacılık sektöründe bir uygulama. Akademik Araştırmalar ve Çalışmalar Dergisi, 1(1), 16-29.

Kanbur, A., \& Kanbur, E. (2015). Lider-üye etkileşiminin örgütsel sinizme etkisi: algılanan içsellik statüsünün aracılık rolü. Zeitschrift für die Welt der Türken/Journal of World of Turks, 7(2), 193-216.

Karanges, E. R. (2014). Optimising employee engagement with internal communication: a social exchange perspective, Doktora Tezi, Queensland University of Technology.

Kassing, J. W. (2000). Investigating the relationship between superior-subordinate relationship quality and employee dissent. Communication Research Reports, 17(1), 58-69.

Katz, D., \& Kahn, R. L. (1966). The social psychology of organizations. New York: Wiley

Kaufman, B. E. (2015). Theorising determinants of employee voice: An integrative model across disciplines and levels of analysis. Human Resource Management Journal, 25(1), 19-40.

Khan, N. A., Khan, A. N., \& Gul, S. (2019). Relationship between perception of organizational politics and organizational citizenship behavior: testing a moderated mediation model. Asian Business \& Management, 18(2), 122-141.

Knapp, J. R., Smith, B. R., \& Sprinkle, T. A. (2014). Clarifying the relational ties of organizational belonging: Understanding the roles of perceived insider status, psychological ownership, and organizational identification. Journal of Leadership \& Organizational Studies, 21(3), 273-285.

Kodaş, B. (2018). Yiyecek içecek çalışanlarının pozitif psikolojik sermayeleri ile işe angaje olma davranışları arasındaki ilişki. Kırklareli Üniversitesi Sosyal Bilimler Dergisi, 2(1), 1-14.

Kwon, B., Farndale, E., \& Park, J. G. (2016). Employee voice and work engagement: Macro, meso, and micro-level drivers of convergence?. Human Resource Management Review, 26(4), 327-337.

Lapalme, M. Ė., Stamper, C. L., Simard, G., \& Tremblay, M. (2009). Bringing the outside in: Can "external” workers experience insider status?. Journal of Organizational Behavior: The International Journal of Industrial, Occupational and Organizational Psychology and Behavior, 30(7), 919-940.

Leiter, M. P., \& Maslach, C. (1988). The impact of interpersonal environment on burnout and organizational commitment. Journal of Organizational Behavior, 9, 297-308.

Leiter, M. P., \& Maslach, C. (2005). A mediation model of job burnout. A. S. G. Antoniou \& C. L. Cooper (Eds.), Research companion to organizational health psychology (544-564). Cheltenham, United Kingdom: Edward Elgar.

Li, J., Wu, L. Z., Liu, D., Kwan, H. K., \& Liu, J. (2014). Insiders maintain voice: A psychological safety model of organizational politics. Asia Pacific Journal of Management, 31(3), 853-874.

Macey, W. H., \& Schneider, B. (2008). The meaning of employee engagement. Industrial and Organizational Psychology, 1(1), 3-30.

Maslach, C., \& Goldberg, J. (1998). Prevention of burnout: New perspectives. Applied and Preventive Psychology, 7, 63-74.

Maslach, C., \& Leiter, M. P. (2008). Early predictors of job burnout and engagement. Journal of Applied Psychology, 93(3), 498-512.

Maslach, C., Jackson, S. E., Leiter, M. P., Schaufeli, W. B., \& Schwab, R. L. (1986). Maslach burnout inventory (Vol. 21, 3463-3464). Palo Alto, CA: Consulting Psychologists Press.

May, D. R., Gilson, R. L., \& Harter, L. M. (2004). The psychological conditions of meaningfulness, safety and availability and the engagement of the human spirit at work. Journal of Occupational and Organizational Psychology, 77(1), 11-37.

Milliken, F. J., Schipani, C. A., Bishara, N. D., \& Prado, A. M. (2015). Linking workplace practices to community engagement: The case for encouraging employee voice. Academy of Management Perspectives, 29(4), 405-421.

Mirap, S. O. (2008). Algılanan aidiyet durumunun görev performansı, bağlamsal performans ve toplam performans üzerine etkilerini ölçmeye yönelik özel sağlık kurumlarında bir araştırma. 16. Ulusal Yönetim ve Organizasyon Kongresi Bildirileri, 16-18 Mayıs, İstanbul, 142-148.

Morrison, E. W. (2011). Employee voice behavior: Integration and directions for future research. Academy of Management Annals, 5(1), 373-412.

Ouyang, K., Lam, W., \& Wang, W. (2015). Roles of gender and identification on abusive supervision and proactive behavior. Asia Pacific Journal of Management, 32(3), 671-691.

Örnek, A. Ş., \& Ayas, S. (2015). Entelektüel sermaye ile yenilikçi iş davranışının işletme performansına etkisi: bilişim sektörü uygulaması. Dokuz Eylül Üniversitesi İşletme Fakültesi Dergisi, 16(2), 91-116.

Özer, Ö., Saygıll, M., \& Uğurluoğlu, Ö. (2015). Sağlık çalışanlarının işe cezbolma düzeylerinin belirlenmesine ilişkin bir araştırma. Business \& Management Studies: An International Journal, 3(3), 261-272.

Özkalp, E., \& Meydan, B. (2015). Schaufeli ve Bakker tarafindan geliştirilmiş olan İşe Angaje Olma ölçeğinin Türkçe'de güvenilirlik ve geçerliliğinin analizi. IŞGUC The Journal of Industrial Relations and Human Resources, 17(3), 1-19.

Öztürk, R., \& Çoban, S. (2019). Political marketing, word of mouth communication and voter behaviours interaction. Business and Economics Research Journal, 10(1), 245-258.

Rees, C., Alfes, K., \& Gatenby, M. (2013). Employee voice and engagement: connections and consequences. The International Journal of Human Resource Management, 24(14), 2780-2798. 
Rothmann, S. (2014). Employee engagement in a cultural context. Catherine Truss, Kerstin Alfes, Rick Delbridge, Amanda Shantz, Emma Soane (Eds.), Employee engagement in theory and practice, 163-179.

Ruck, K., Welch, M., \& Menara, B. (2017). Employee voice: An antecedent to organisational engagement?. Public Relations Review, 43(5), 904-914.

Saks, A. M. (2006). Antecedents and consequences of employee engagement. Journal of Managerial Psychology, 27(1), 600-619.

Schaufeli, W. B., \& Bakker, A. B. (2003). Utrecht work engagement scale: Preliminary manual. Occupational Health Psychology Unit, Utrecht University, Utrecht, 26, 64.

Schaufeli, W. B., Bakker, A. B., \& Salanova, M. (2006). The measurement of work engagement with a short questionnaire: A crossnational study. Educational and psychological measurement, 66(4), 701-716.

Schaufeli, W. B., Bakker, A. B., \& Van Rhenen, W. (2009). How changes in job demands and resources predict burnout, work engagement, and sickness absenteeism. Journal of Organizational Behavior: The International Journal of Industrial, Occupational and Organizational Psychology and Behavior, 30(7), 893-917.

Schaufeli, W. B., Salanova, M., González-Romá, V., \& Bakker, A. B. (2002). The measurement of engagement and burnout: A two sample confirmatory factor analytic approach. Journal of Happiness studies, 3(1), 71-92.

Schaufeli, W. B., Taris, T. W., \& Van Rhenen, W. (2008). Workaholism, burnout, and work engagement: Three of a kind or three different kinds of employee well-being?. Applied Psychology, 57(2), 173-203.

Stamper, C. L., \& Masterson, S. S. (2002). Insider or outsider? How employee perceptions of insider status affect their work behavior. Journal of Organizational Behavior: The International Journal of Industrial, Occupational and Organizational Psychology and Behavior, 23(8), 875-894.

Şehitoğlu, Y., \& Zehir, C. (2010). Türk kamu kuruluşlarında çalışan performansının, çalışan sessizliği ve örgütsel vatandaşlık davranışı bağlamında incelenmesi. Amme İdaresi Dergisi, 43(4), 87-110.

Turgut, T. (2011). Çalışmaya tutkunluk: iş yükü, esnek çalışma saatleri, yönetici desteği ve iş-aile çatışması ile ilişkileri. Atatürk Üniversitesi İktisadi ve İdari Bilimler Dergisi, 25(3-4), 155-179.

Uyar, S., \& Güzel, Ş. (2019). İşe angaje olmak kavramı, tükenmişlik ile ilişkisi ve sonuçları. Sosyal Araştırmalar ve Yönetim Dergisi, (1), 44-52.

Van Dyne, L., \& LePine, J. A. (1998). Helping and voice extra-role behaviors: Evidence of construct and predictive validity. Academy of Management Journal, 41(1), 108-119.

Van Dyne, L., Ang, S., \& Botero, I. C. (2003). Conceptualizing employee silence and employee voice as multidimensional constructs. Journal of Management Studies, 40(6), 1359-1392.

Wood, S. J., \& Fenton-O'Creevy, M. P. (2005). Direct involvement, representation and employee voice in UK multinationals in Europe. European Journal of Industrial Relations, 11(1), 27-50.

Xanthopoulou, D., Bakker, A. B., Demerouti, E., \& Schaufeli, W. B. (2009). Reciprocal relationships between job resources, personal resources, and work engagement. Journal of Vocational Behavior, 74(3), 235-244.

Xiao, Y., Ping, S., \& Le, T. (2015). Leader-member exchange social comparison, perceived insider status and employee's job performance: The role of LMX differentiation. Nankai Business Review, 18(4), 26-35.

Zhu, Y., Zhang, S., \& Shen, Y. (2019). Humble leadership and employee resilience: exploring the mediating mechanism of work-related promotion focus and perceived insider identity. Frontiers in Psychology, 1-10. 